\title{
Matrix of Photosensitive Elements for Determining the Coordinates of the Source of Optical Radiation
}

\author{
V.G. Verbitskiy, V.S. Antonyuk, A.O. Voronko*, L.M. Korolevych, D.V. Verbitskiy, D.O. Novikov \\ National Technical University of Ukraine "Igor Sikorsky Kyiv Polytechnic Institute", \\ 37, Peremohy Ave, 03056 Kyiv, Ukraine
}

(Received 22 June 2021; revised manuscript received 10 August 2021; published online 20 August 2021)

\begin{abstract}
This paper presents new position-sensitive matrices of photosensitive elements. The photosensitive elements of the proposed matrix can be manufactured, depending on the required spectral range, based on $\mathrm{Si}, \mathrm{A}_{3} \mathrm{~B}_{5}$ solid solutions, etc. Depending on the required technical characteristics, PN photodiodes, PIN photodiodes, or avalanche photodetectors can be used as photosensitive elements. The main advantage of the proposed optical coordinator is a special topology of connection of sensitive elements. The interlaced connection of rows and columns allows to significantly reduce the number of information outputs, expand the dynamic range, and achieve greater manufacturability of the device without significant loss of the signal component. The periodicity of the topology makes it possible to find the position of a light spot, determine its center, and accurately track the movement of the spot along the coordinator without the use of micromechanical centering devices. The "checkerboard" topology of the sensitive elements and method of generating output signals are discussed. Such an arrangement makes it possible to simultaneously determine two coordinates at the same time. Methods for determining the center of a light spot are presented as well. The overlap of the area of the sensitive element by the light spot is proportional to the output current signal. Therefore, it is possible to determine the center of the light spot by solving a two-dimensional geometric problem. The distribution of errors in determining the center was calculated using the method of finding the barycenter in dynamic and statistical modes for different light spot configurations. Directionfinding characteristics were analyzed. A topology of connection that allows to expand the dynamic range of the measurement was submitted.
\end{abstract}

Keywords: Optical coordinator, Position sensitive matrix, Photodiode, Position sensitive device (PSD), Method for determining coordinates, Quadrant photodiodes (QPD), Direction-finding characteristics.

\section{INTRODUCTION}

Precision optical coordinators are widely used to determine micromovements. The main task of the optical coordinator is to precisely determine the spatial position of the light spot, usually formed by a laser diode or LED with collimating optics and the corresponding radiation spectrum. Usually, such systems use one- or two-dimensional position-sensitive photodetectors (PSD): CCD; active pixel sensors (APS), which include CMOS Image Sensors (CIS) [1-4]; photodiodes based on the lateral effect [5-9]. All of the above types of detectors have a number of technical disadvantages (low speed, sensitivity and accuracy, exposure to light), which in some cases, restrict their use. It is better to use quadrant photodiodes (QPD) for precise determination of the coordinates of the light spot [10-12].

\section{FORMULATION OF THE PROBLEM}

The four-quadrant photodetector has a good resolution of the position of a light spot (high steepness of the direction-finding characteristic) in a relatively small range (movement does not exceed the size of the radius of the light spot) relative to the center. Therefore, the functional diagram of the optical coordinator, based on the four-quadrant photodetector, must necessarily include a tracking system. Precision tracking systems are specially used to maintain the light spot in the center of the four-quadrant photodiode [13]. Optical coordinators of this type are used in many measuring systems, where it is necessary to determine the coordinates of a light spot very accurately. For example, the optical coordinator for determining the coordinates of a reflected beam from a cantilever in an atomic force microscope is arranged according to this scheme. To increase the capture area of the tracking system, it is necessary to form a light spot of larger diameter. At the same time, the steepness of the direction-finding characteristic (dependence of the amplitude of the output signals of the photosensitive elements on the position of the light spot on it) and, consequently, holding accuracy of the light spot in the nominal position depends on the size ratio between the light spot and quadrants of the photodetector. Reducing the diameter of the light spot increases the measurement resolution of the optical coordinator. In this case (as in the case of a four-quadrant photodetector), it is necessary to use $\mathrm{X}-\mathrm{Y}$ micromanipulators for greater tracking accuracy of the optical coordinator. Thus, providing both a large width of the capture area and high accuracy of determining the coordinates of the light spot at the same time are contradictory requirements that cannot be realized using a four-quadrant photodetector as a position-sensitive element. For this reason, these optical coordinators always require an initial precision alignment of the light beam position.

In some cases, extremely high requirements are imposed on the dynamic range of optical coordinators, which are practically unattainable with known construction

\footnotetext{
*a7@ukr.net
} 
schemes. In known schemes for constructing optical coordinators, the optical system focuses radiation into a spot whose size is smaller than one photosensitive element. It turns out that at the required minimum level of the optical signal, it is impossible to meet the requirements for the signal-to-noise ratio, and at a given level of the maximum optical signal, the photosensitive elements of the matrix would be destroyed.

\section{THE GOAL OF THE WORK}

The purpose of this work is to develop a positionsensitive photodetector array for an optical coordinator with a large capture area and high accuracy in determining the position of the light spot, if possible, with a minimum number of processed signals from a positionsensitive element, i.e., essentially creating a precision optical coordinator without a tracking system and initial alignment of a light beam. It is also necessary to develop a photosensitive matrix with an extended dynamic range for measuring the position of a radiation source with an optical signal not normalized in power.

\section{PHOTOSENSITIVE ARRAY TOPOLOGY}

To create an optical coordinator without a tracking system, it is necessary to resolve the contradiction between the accuracy of determining the position of the light spot and the capture area of the optical coordinator. To solve this problem, a new method is proposed for determining the coordinates of the light spot and using a position-sensitive matrix of photosensitive elements with a special topology of photosensitive elements interconnections, which simultaneously provides both a high slope of the direction-finding characteristic and a wide capture zone of the tracking system. According to the proposed topology, the photosensitive elements are arranged in rows and columns like a "checkerboard", and the photosensitive elements located on the "white" fields are connected into columns, and those located on the "black" fields - into rows (Fig. 1).

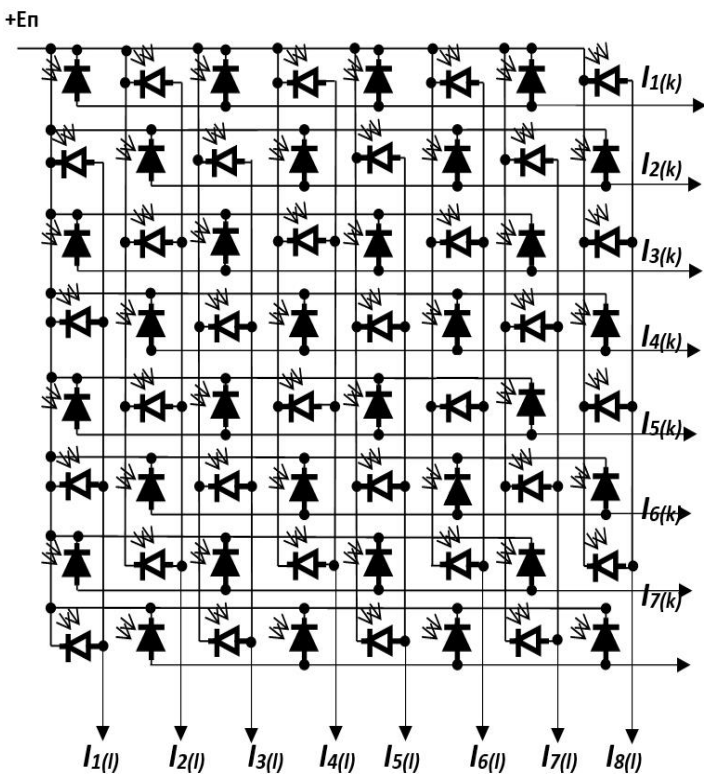

Fig. 1 - Diagram of a position-sensitive matrix of photosensitive elements
Photocurrents of elements of each row (column) located after one are summed up. Thus, at the outputs of the proposed matrix, signals are generated equal to the sum of photocurrents from the elements of the corresponding rows (columns) of this matrix:

$$
\begin{gathered}
I_{2 k-1}=\sum_{l=1}^{\frac{n}{2}} I_{(2 k-1),(2 l-1)}, \\
I_{2 k}=\sum_{l=1}^{\frac{n}{2}} I_{2 k, 2 l}, \\
I_{2 l-1}=\sum_{k=1}^{\frac{m}{2}} I_{2 k,(2 l-1)}, \\
I_{2 l}=\sum_{k=1}^{\frac{m}{2}} I_{(2 k-1), 2 l},
\end{gathered}
$$

where $m$ is the number of matrix rows, $n$ is the number of matrix columns,

$$
k=1,2,3, \ldots, \frac{m}{2} \quad l=1,2,3, \ldots, \frac{n}{2} .
$$

Note that in such a matrix, the number of rows and columns is not limited by the requirement of multiplicity 4 but can be arbitrary.

\section{DETERMINATION OF COORDINATES USING MATRIX. ANALYSIS OF DIRECTION- FINDING CHARACTERISTICS}

\subsection{Determining Coordinates Using a Matrix}

The regularity of the sensitive elements allows to bind the optical coordinator to the Cartesian coordinate system and turn the search for $x$ and $y$ coordinates into a solution of a geometric problem. The requirement for the size of the light spot is the diameter, the value of which is greater than one element of the sensitive matrix. This requirement is the minimum threshold for the simultaneous determination of coordinates in twodimensional space.

The spot diameter can be varied (Fig. 2), therefore the following classification is proposed: $1 p, 2 p, \ldots, N p$, where $p$ denotes the area of $1,2, \ldots, N$ sensitive elements. The maximum value for the spot to overlap the element's area is 2401 .

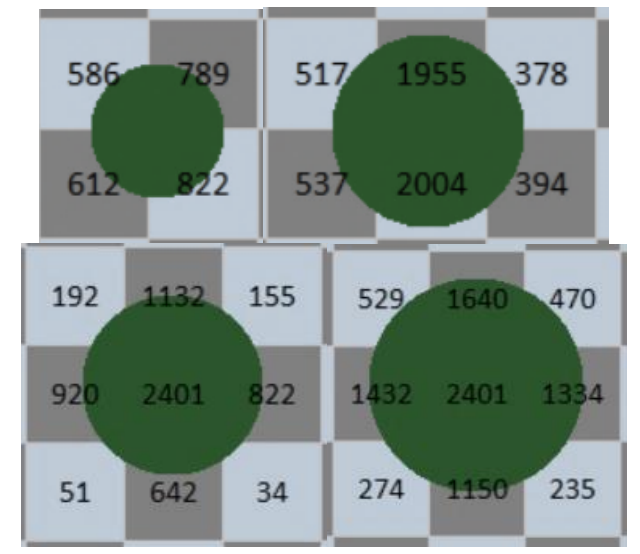

Fig. $2-2 p, 3 p, 4 p, 5 p$ light spot configurations 
The output photocurrent of the sensitive element is proportional to the overlap of the element's area by the light spot. So, it can be assumed that the position of the energy center of the spot is in the region of the elements with the highest output signal.

The direct detection method consists in alternating scanning of $l$-elements to determine a preliminary spot size and radiation distribution along the $X$-axis and $k$ elements along the $Y$-axis, followed by normalization with respect to the sum of the total radiation power $P$.

An $8 \times 8$ simplified matrix of sensitive elements with an element size of $10 \times 10$ conventional units and a technological gap of 2 conventional units is presented (Fig. 3). The light spot has a $5 p$ configuration and a uniform distribution, the diameter value is 23 conventional units.

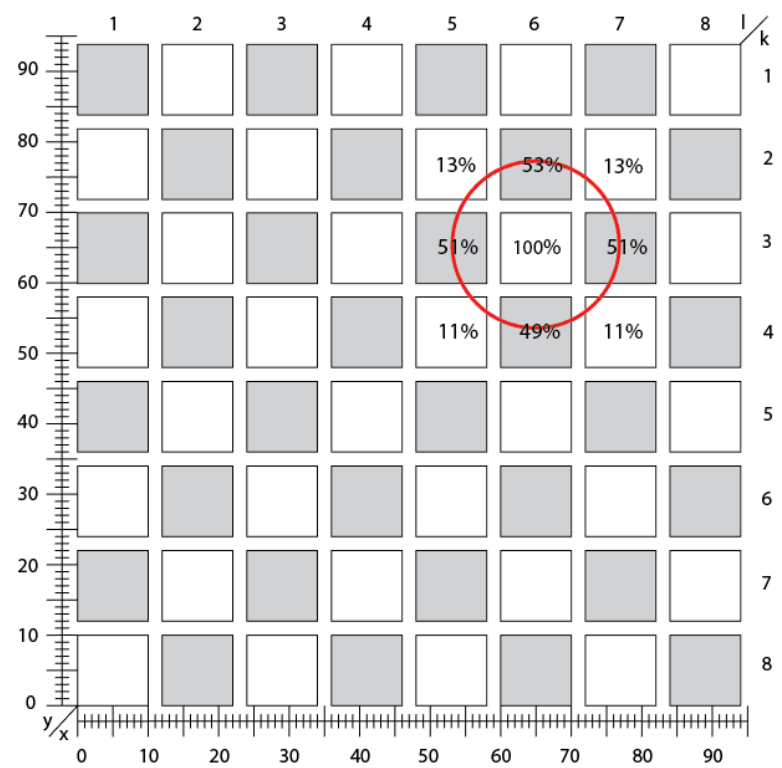

Fig. 3 - Simplified matrix of the sensitive elements

Due to the scheme of the optical coordinator (Fig. 1) and the simplified matrix (Fig. 3), the following results are presented.

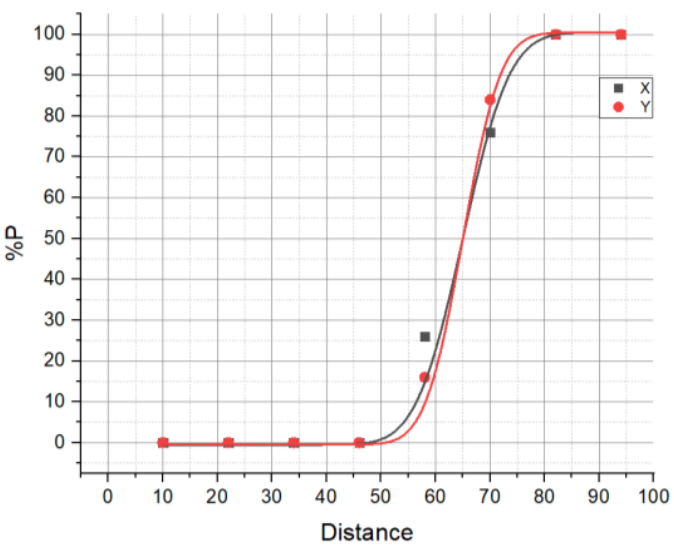

Fig. 4 - Spatial distribution of radiation

Using this method, it can be argued that the size of the light spot is approximately $3 \times 3$ elements wide. According to the distribution graph, the coordinates of the energy center are located near the $50 \% P$ point and the accuracy of its determination depends on the approximation errors and light spot configuration. To improve the precision, this method requires a decrease in the size of the sensitive elements or an increase in the spot diameter, which in some cases is not rational. Also, this method is not applicable if part of the spot is outside the sensitive part of the optical coordinator. However, this method can be used to roughly determine the spot size and its center at the stages of setting up the optical coordinator.

Table 1 - Matrix output

\begin{tabular}{|c|c|c|c|c|c|}
\hline & \multicolumn{2}{|c|}{ Output signal } & \multicolumn{3}{c|}{ Spatial distribution } \\
\hline № & Rows $(X)$ & Columns $(Y)$ & Distance & $\% P X$ & $\% P Y$ \\
\hline 1 & 0 & 0 & 10 & 0 & 0 \\
\hline 2 & 0 & 24 & 22 & 0 & 0 \\
\hline 3 & 0 & 100 & 34 & 0 & 0 \\
\hline 4 & 0 & 24 & 46 & 0 & 0 \\
\hline 5 & 53 & 0 & 58 & 26 & 16 \\
\hline 6 & 102 & 0 & 70 & 76 & 84 \\
\hline 7 & 49 & 0 & 82 & 100 & 100 \\
\hline 8 & 0 & 0 & 94 & 100 & 100 \\
\hline
\end{tabular}

Centroid method is to find the barycenter of the figure, which was formed as a result of the overlap of the spot and the sensitive elements. In turn, the center of a fully filled element $\left(x_{0} ; y_{0}\right)$ can be calculated as:

$$
\begin{aligned}
& x_{0}=\frac{x_{n}+x_{k}}{2} ; \\
& y_{0}=\frac{y_{n}+y_{k}}{2} .
\end{aligned}
$$

$x_{n}, y_{n}, x_{k}, y_{k}$ are the coordinates of the element sides.

The centroid of a plane figure $\left(x_{c} ; y_{c}\right)$ can be calculated by geometric decomposition:

$$
\begin{aligned}
& x_{c}=\frac{\sum x_{i} S_{i}}{\sum S_{i}} ; \\
& y_{c}=\frac{\sum y_{i} S_{i}}{\sum S_{i}} .
\end{aligned}
$$

$x_{i}, y_{i}, S_{i}$ are the coordinates and areas of each part.

To calculate the error and for further analysis, software was created to simulate the determination of the center of the light spot in dynamic and statistical modes. To calculate the error in statistical analysis, a randomly specified position of the spot is used in the given coordinates of the matrix, where the number of positions is 500. For dynamic analysis, the position of the spot changes slightly and randomly in a given direction, simulating work in real conditions. The results are given below (Fig. 5).

For the dynamic mode, the results were averaged and collected in a Table 2 .

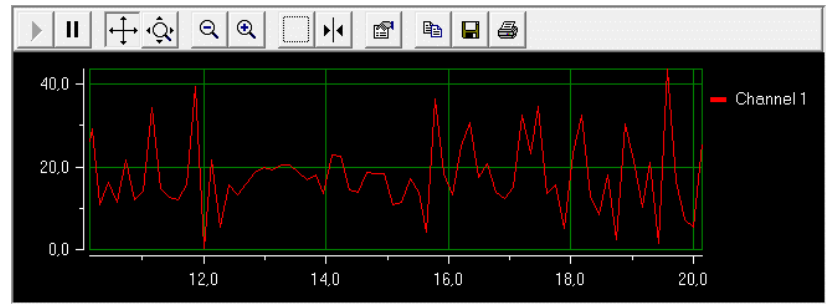



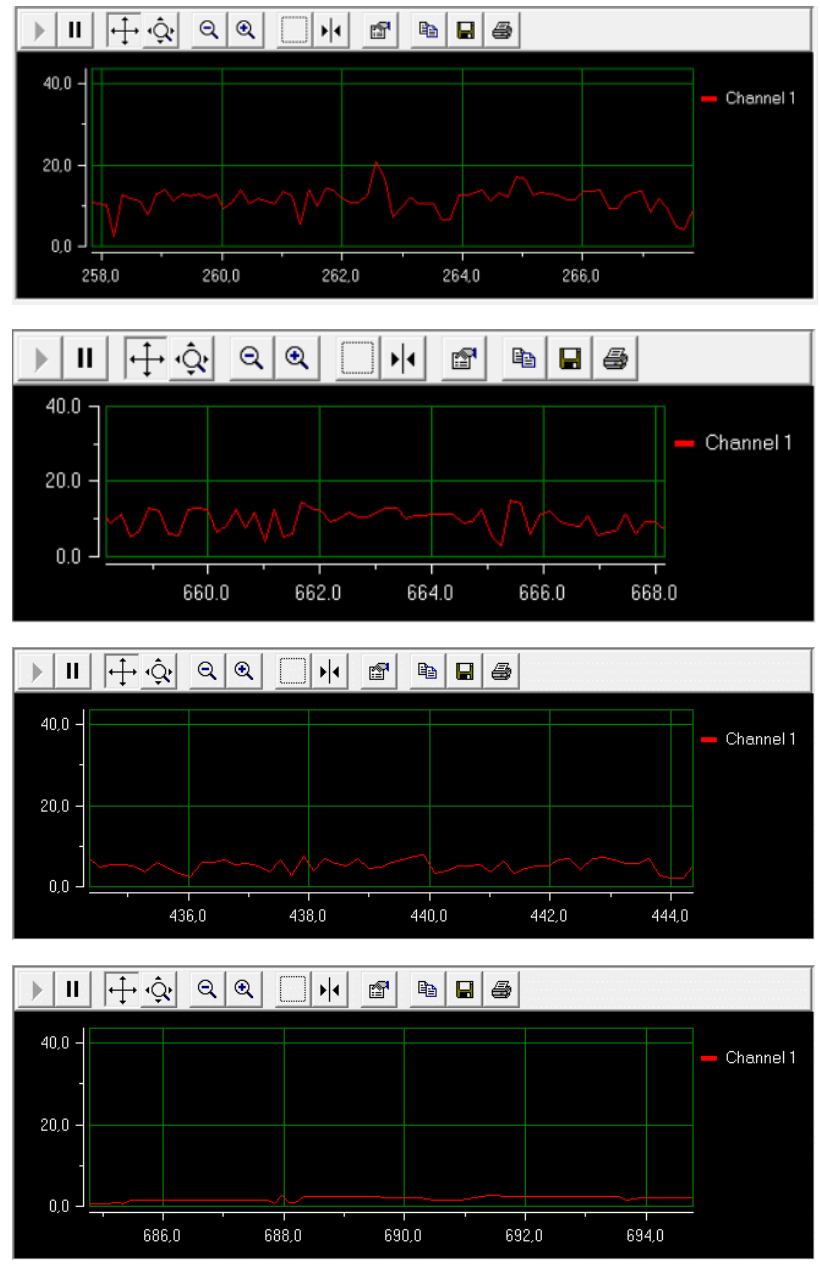

Fig. 5 - Static error distribution for $1 p, 2 p, 3 p, 4 p, 5 p$ spot configurations

Table 2 - Average overlap errors

\begin{tabular}{|c|c|}
\hline Overlap & Average error, $\%$ \\
\hline $1 p$ & 19 \\
\hline $2 p$ & 14 \\
\hline & 12 \\
\hline $3 p$ & 10 \\
\hline $4 p$ & 9.4 \\
\hline $5 p$ & 4.8 \\
\hline & 1.1 \\
\hline
\end{tabular}

Therefore, the spot with overlap configuration $5 p$ has the greatest accuracy, but configurations $4 p$ and below are of the greatest interest. Further research will be conducted to improve their accuracy and the calculation algorithm. It is also planned to develop an algorithm for calculating the center of the spot, part of which extends beyond the sensitive area of the coordinator.

\subsection{Analysis of Direction-finding Characteristics}

By the direction-finding characteristics of the optical coordinator, we mean a set of dependences of the electrical signals FE $i$ and FEj from the outputs of the position-sensitive matrix of photosensitive elements with a special topology of interconnections, on the basis of which the coordinator is built, on the angular coordinates $\alpha, \beta$ of the beam incident on the matrix:

$$
\left.\begin{array}{cc}
F E i_{1}(\alpha, \beta) ; & F E j_{1}(\alpha, \beta) ; \\
F E i_{2}(\alpha, \beta) ; & F E j_{2}(\alpha, \beta) ; \\
\ldots & \ldots \\
F E i_{N}(\alpha, \beta) ; & F E j_{N}(\alpha, \beta)
\end{array}\right\}
$$

The direction-finding characteristics $F E i$ and $F E j$ of the optical coordinator are completely determined by the corresponding direction-finding characteristics FSi and $F S j$ of the position-sensitive matrix:

$$
\left\{\begin{array}{cc}
F S i_{1}\left(x_{O}, y_{O}\right) ; & F S j_{1}\left(x_{O}, y_{O}\right) ; \\
F S i_{2}\left(x_{O}, y_{O}\right) ; & F S j_{2}\left(x_{O}, y_{O}\right) ; \\
\ldots & \ldots \\
F S i_{N}\left(x_{O}, y_{O}\right) ; & F S j_{N}\left(x_{O}, y_{O}\right)
\end{array}\right\}
$$

Here FSi is the total electrical signal from the matrix output corresponding to its $i$-th row; $\mathrm{FS} j$ is the total electrical signal from the output corresponding to its $j$-th column; $x$ is the linear coordinate of the center of the light spot $\mathrm{O}$ along the axis perpendicular to the direction of the matrix rows; $y$ is the linear coordinate of the center of the light spot $\mathrm{O}$ along the axis perpendicular to the direction of the matrix columns.

In this case, it is sufficient to determine the direction-finding characteristics $\mathrm{FS} i$ and $\mathrm{FS} j$ of the positionsensitive matrix on the interval in the matrix plane corresponding to a square with a half-period size $d$ of the matrix for the coordinate plane $O x y$ with the origin at the center of the matrix element:

$$
\left\{\begin{array}{l}
x_{O} \in\left[-\frac{d}{2} ;+\frac{d}{2}\right] \\
y_{O} \in\left[-\frac{d}{2} ;+\frac{d}{2}\right] .
\end{array}\right.
$$

The periodicity and evenness/oddness of the direction-finding characteristics FSi and FSj of the positionsensitive matrix of photosensitive elements with a special topology of interconnections is manifested in the following properties:

$$
\begin{aligned}
& {\left[F i_{I}\left(x_{O}+d, y_{O}\right)=F \operatorname{Sj}_{J}\left(y_{O}, x_{O}\right) ;\right.} \\
& \left.F \operatorname{Fi}_{I}\left(x_{O}, y_{O}+d\right)\right)=F \operatorname{Sj}_{J-1}\left(y_{O}, x_{O}\right) \text {; } \\
& F S i_{I}\left(x_{O}+d, y_{O}+d\right)=F S i_{I-1}\left(x_{O}, y_{O}\right) \text {; } \\
& F \operatorname{Fj}_{J}\left(x_{O}+d, y_{O}\right)=F S i_{I-1}\left(y_{O}, x_{O}\right) \text {; } \\
& \left.F \operatorname{Fj}_{J}\left(x_{O}, y_{O}+d\right)\right)=F i_{I}\left(y_{O}, x_{O}\right) \text {; } \\
& F \operatorname{Fj}_{J}\left(x_{O}+d, y_{O}+d\right)=F S j_{J-1}\left(x_{O}, y_{O}\right) \\
& F \operatorname{FSi}_{I}\left(x_{O}+2 d, y_{O}\right)=F S i_{I-2}\left(x_{O}, y_{O}\right) \text {; } \\
& \left.F \operatorname{Fii}_{I}\left(x_{O}, y_{O}+2 d\right)\right)=F S i_{I}\left(x_{O}, y_{O}\right) \text {; } \\
& F S i_{I}\left(x_{O}+2 d, y_{O}+2 d\right)=F S i_{I-2}\left(x_{O}, y_{O}\right) \text {; } \\
& F \operatorname{Fj}_{J}\left(x_{O}+2 d, y_{O}\right)=F \operatorname{Fj}_{J}\left(x_{O}, y_{O}\right) \text {; } \\
& \left.F \operatorname{Fj}_{J}\left(x_{O}, y_{O}+2 d\right)\right)=F S_{J-2}\left(x_{O}, y_{O}\right) \text {; } \\
& F S_{J}\left(x_{O}+2 d, y_{O}+2 d\right)=F S j_{J-2}\left(x_{O}, y_{O}\right)
\end{aligned}
$$

where $i$ is the row number of the matrix element on which the center of the light spot with coordinates $x, y$ is located; $j$ is the column number of the matrix element on which the center of the light spot with coordinates $x, y$ is located. 
The optical signal on each matrix element is the luminous flux incident on the photosensitive area of the element, proportional to the illuminated area of this element. The electrical signal-response from each photosensitive element of the matrix is proportional to the optical signal arriving at it. Photocurrent $I_{i, j}$ from each matrix element is determined by the integral

$$
I_{i, j}=k \int_{y 1_{i j}}^{y 2_{i j}} \int_{x 1_{i j}}^{x 2_{i j}} E(x, y) d x d y .
$$

Here $i, j$ is the address of the matrix element by the row and column numbers; $k$ is the coefficient of proportionality (current photosensitivity); $E(x, y)$ is the illumination in the spot; $x 1_{i, j}, x 2_{i, j}$ are the coordinates of the left and right boundaries of the photosensitive area $i, j$ of the element; $y 1_{i, j}, y 2_{i, j}$ are the coordinates of the upper and lower boundaries of the photosensitive area $i, j$ of the element.

In the mathematical model, we consider a matrix of photosensitive elements of a square shape of size $a \times a$ with gaps of width $t$ between them, on the surface of which an optical signal arrives in the form of a circular light spot of diameter $D$ with a normal (according to the Gaussian) distribution of illumination $E$ in it. In this case, the illumination at an arbitrary point of a round light spot is determined by the formula:

$$
E(x, y)=E_{0} \frac{1}{\sigma \sqrt{2 \pi}} e^{-\frac{x^{2}+y^{2}}{2 \sigma^{2}}},
$$

where $E_{0}$ is the illumination at the center of the light spot; $\sigma$ is the Gaussian distribution parameter; $x, y$ are the coordinates of an arbitrary point in the Cartesian coordinate system with the origin in the center of the light spot $\mathrm{O}$. Then the electrical signal-response from each photosensitive element of the matrix according to (11) is determined by the integral

$$
I_{i, j}=k \int_{y 1_{i j}}^{y 2_{i j}} \int_{x 1_{i j}}^{x 2_{i j}} E_{0} \frac{1}{\sigma \sqrt{2 \pi}} e^{-\frac{x^{2}+y^{2}}{2 \sigma^{2}}} d x d y .
$$

If we consider the direction-finding characteristics of such a matrix as the dependence of the output electrical signals on the coordinates of the center of the light spot on the matrix, then it can be argued that these characteristics are described by periodic functions with a period corresponding to the spatial period of a matrix with a checkerboard structure:

$$
T=2(a+t) .
$$

To study the direction-finding characteristics, it is sufficient to investigate the dependence of the output electrical signals from the matrix on the coordinates of the center of the light spot, which moves within the matrix area with dimensions $T \times T$.

For the functional representation of the directionfinding characteristics of the position-sensitive matrix of photosensitive elements, the obtained dependences are approximated by a known technique, for example, by a polynomial of two variables of degree $2(n-1)$. Polynomials that interpolate the dependence of the direction-finding characteristics (3) of the matrix are graphically represented as a surface in the Cartesian rectangular coordinate system $O x y z$. In this case, the $x$ coordinate of each surface point in the $3 \mathrm{D}$ graph corresponds to the $x$ coordinate of the center of the light spot, the $y$ coordinate corresponds to the $y$ coordinate of the center of the light spot, and the $z$ coordinate - to the value of the corresponding dependence of the direction-finding characteristics of the matrix (the total electrical signal from the corresponding outputs of rows and columns of the matrix).

To increase the dynamic range of the optical coordinator, a fundamentally new topology of interconnections of light-sensitive semiconductor elements of a positionsensitive matrix was proposed [14]. The photosensitive elements of the proposed matrix can be made depending on the required spectral range based on $\mathrm{Si}, \mathrm{A}_{3} \mathrm{~B}_{5}$ solid solutions, etc. An increase in the dynamic range is achieved due to the fact that a light spot with a size of at least $2 \times 2$ matrix elements is formed on the matrix surface; to increase the speed, PIN, MPM or MDP, avalanche photodetectors can be used as photosensitive elements. Photosensitive elements are organized in rows and columns according to the proposed topology (similar to the previous topology). The electrical signals from the elements of each row (column) are summed up, and the electrical signals from the elements of adjacent even (odd) rows (columns) are subtracted (Fig. 6).

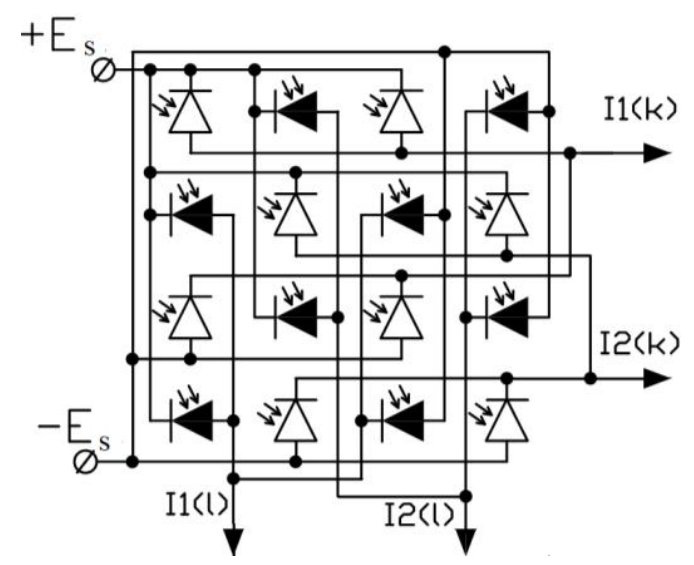

Fig. 6-Schematic diagram of a position-sensitive array of photosensitive elements with an extended dynamic range

Due to this, electrical signals are generated at each of the matrix outputs, proportional to the difference in illumination of all photosensitive elements of adjacent even (odd) rows (columns) of such a matrix. The use of the proposed interconnection topology makes it possible to determine simultaneously both coordinates of the light spot on one matrix of $N \times M$ elements with an accuracy of one matrix element. At the same time, for processing analog signals from a $4 N \times 4 M$ matrix, only $2 N+2 M$ independent channels are enough to amplify the signal. To convert the received signals into a digital code, $4 N \times 4 M$ comparators and two encoders (with $4 N$ and $4 M$ inputs, respectively) are used. Note that these same encoders easily solve the task of transforming these coordinates (for example, from coordinates relative to the matrix to coordinates relative to the carrier of this matrix). 


\section{CONCLUSIONS}

The original position-sensitive matrix elements with a direction-finding characteristic comparable to a fourquadrant photodetector is proposed for the optical coordinator without using a precision tracking electromechanical system for holding the light spot near the center of the photodetector element. In this case, there is also no need for initial alignment of the optical coordinator with the analyzed beam. The matrix topology has made it possible to significantly reduce the number of processed analog signals from photosensitive elements, which greatly simplifies the signal processing algorithm for determining the coordinates of the light spot.

\title{
REFERENCES
}

1. M. Huber, et al, CCD and CMOS sensors, In: Observing Photons in Space ISSI Scientific Reports Series (ESA/ISSI: 2010).

2. F. De Nisi, F. Comper, L. Gonzo, M. Gottardi, D. Stoppa, A. Simoni, J.A. Beraldin, IEEE J. Sensors 5 No 6, 1296 (2005).

3. Xunjun Qi, et al., Opt. Eng. 45 No 1, 014402 (2006).

4. F. Michael, et al., IEEE Trans. Electron Dev. 56 No 11, 2623 (2009).

5. J. Henry, J. Livingstone, phys. status solidi a 208, 1718 (2011).

6. H.X. Song, Wang, et al., J. Phys.: Conf. Ser. 48, 217 (2006).

7. W. Wang, I.J. Busch-Vishniac, IEEE Trans. Electron Dev. 36 No 11, 2475 (1989).

8. H. Andersson, et al., IEEE Sensors J. 8 No 10, 1704 (2008).

9. A. Dlugaszek, J. Jabczynski, J. Janucki, W. Skrzeczanowski, Semiconductor Physics, Quantum Electronics \& Optoelectronics 2 No 3, 71 (1999).

10. L.P. Salles, D.W. de Lima Monteiro, IEEE Sensors J. 10 No 2, 286 (2010).

11. C.F. Kuang, et al., Opt. Techn. 30 No 4, 387 (2004).

12. T. Ng, H. Tan, S. Foo, Opt. Laser Technol. 39 No 5, 1098 (2007).

13. Yu.M. Astapov, D.V. Vasiliev, Yu.I. Zalozhnev, The Theory of Optoelectronic Tracking Systems (Moscow: Nauka: 1988).

14. A. Voronko, M. Moskalenko, G. Potapova, III International Conference on Optoelectronic Information Technologies "Photonics-ODS 2005", 201 (Vinnytsia: 2005).

\section{Матриця фоточутливих елементів для визначення координат джерела оптичного випромінювання}

\author{
В.Г. Вербицький, В.С. Антонюк, А.О. Воронько, Л.М. Королевич, Д.В. Вербицький, Д.О. Новіков \\ Національний технічний університет України “Київський політехнічний інститут Ігоря Сікорського», \\ проспект Перемоги, 37, 03056 Київ, Україна
}

\begin{abstract}
У роботі представлені результати досліджень щодо розробки конструкції матриці світлочутливих елементів на основі твердих розчинів $\mathrm{Si}$ та сполук $\mathrm{A}_{3} \mathrm{~B}_{5}$ у вигляді $p$ - $n$-фотододісів, pin-фотодіодів або лавинних фотоприймачів. Основною перевагою запропонованої матриці є особлива топологія з'єднання чутливих елементів. Переплетене з'єднання рядків і стовпщів дозволяе значно скоротити кількість вихідних даних, розширити динамічний діапазон і досягти більшої технологічності пристрою без значних втрат компонента сигналу. Періодичність топології дозволяе знаходити положення світлової плями, визначати їі центр і точно відстежувати рух плями вздовж координатора без використання мікромеханічних пристроїв. Обговорюеться топологія «шахової дошки» чутливих елементів та спосіб генерування вихідних сигналів. Таке розташування дає можливість визначати дві координати одночасно. Представлені також методи визначення центру світлової плями. Перекриття області чутливого елемента світловою плямою пропорційне сигналу вихідного струму. Показано, що центр світлової плями можна визначити, вирішивши двовимірну геометричну задачу. Розподіл похибок при визначенні центру розраховувався за допомогою методу знаходження барицентру в динамічному та статистичному режимах для різних конфігурацій світлових плям. Проаналізовано характеристики визначення напрямку сигналу. Представлена топологія з'єднання для розширення динамічного діапазону вимірювань.
\end{abstract}

Ключові слова: Оптичний координатор, Позиційночутлива матриця, Фотодіод, Пристрій з чутливістю до положення (ПЧП), Метод визначення координат, Квадрантні фотодіоди (КФ), Характеристики визначення напрямку. 